\title{
A CFD study of steam injection tubing heat losses
}

\author{
Un estudio de las pérdidas de calor a través de los tubos \\ de inyección de vapor utilizando CFD
}

\author{
Sara Saraiva de Lira Araújo ${ }^{1} \quad$ Oldrich Joel Romero ${ }^{2 *}$
}

Recibido 18 de noviembre de 2017, aceptado 13 de septiembre de 2018

Received: November 18, 2017 Accepted: September 13, 2018

\begin{abstract}
To increase heavy oil production, the petroleum industry uses thermal recovery methods, and the steam injection is one of the most common techniques. Steam generated at the surface reaches the oil reservoir through the injection tubing. Heat transfer between the steam and the injection well surroundings the tubing is analyzed in this work, the challenge in this process to minimize it. It is presented the three-dimensional simulation of the multiphase turbulent liquid-vapor flow along with a $100 \mathrm{~m}$ wellbore domain composed by injection tubing, annular space, casing, and rock formation. With the software ANSYS CFX® 15.0, the response of a low thermal conductivity tubing and formation temperature to steam injection at $80 \%$ of quality, injected at two different flow rates, is evaluated. The insulated material tubing (IMT) has the best performance compared to the conventional configuration, for both $1.2 \mathrm{~kg} / \mathrm{s}$ and $3.3 \mathrm{~kg} / \mathrm{s}$ flow rates. Additionally, the higher flow rate shows higher steam quality results when using a conventional tubing while maintaining $0.13 \%$ more quality at the tubing output.
\end{abstract}

Keywords: Heavy oil, steam injection, heat transfer, ANSYS CFX ${ }^{\circledR} 15.0$, steam quality.

\section{RESUMEN}

Con el objetivo de viabilizar la producción de petróleo pesado, los métodos de recuperación térmica son los más utilizados y dentro de esta categoría la inyección de vapor es una de las técnicas más difundidas. El calor es transportado desde la superficie hasta el subsuelo donde se encuentra el yacimiento que contiene el petróleo. Esta operación es realizada por el vapor generado en superficie utilizando el tubo de inyección como eslabón de conexión superficie-fondo. Se analiza la transferencia de calor entre el vapor y el entorno del pozo de inyección a lo largo del tubo, el desafío en este proceso es minimizarlo. Se presenta la simulación tridimensional del flujo líquido-vapor, turbulento y multifásico a lo largo de un dominio de pozo de 100 m compuesto por tubos de inyección, espacio anular, revestimiento y formación rocosa. Con el software ANSYS CFX® 15.0 se evalúa el desempeño de tuberías de baja y alta conductividad térmica, con vapor al $80 \%$ de calidad, inyectada a dos flujos diferentes. El tubo con aislamiento (IMT) claramente tiene el mejor rendimiento en comparación con la configuración convencional, para ambos flujos de 1,2 kg/s y $3,3 \mathrm{~kg} / \mathrm{s}$. Además, la mayor velocidad de inyección muestra mejores resultados, en términos de la calidad del vapor, cuando se usa una tubería convencional, la calidad en la salida de la tubería es 0,13\% superior.

Palabras clave: Petróleo pesado, inyección de vapor, transferencia de calor, ANSYS CFX ${ }^{\circledR}$ 15.0, calidad de vapor.

1 Departamento de Engenharias e Tecnologia. Universidade Federal do Espírito Santo. Rodovia BR 101 Norte, km 60, Litorâneo, São Mateus, ES, Brasil. CEP 29932-900. E-mail: sara-sla@ hotmail.com

2 Programa de Pós-graduação em Energia. Departamento de Engenharias e Tecnologia. Universidade Federal do Espírito Santo. Rodovia BR 101 Norte, km 60, Litorâneo, São Mateus, ES, Brasil. CEP 29932-900. E-mail: oldrich.romero@ufes.br

* Corresponding Author 


\section{INTRODUCTION}

Oil companies have increased the search for new technologies in order to raise the recovery factor of the oil contained in the reservoirs and reduce the costs of production projects [1, 2, 3, 4]. For the heavy oils production, i.e., extremely viscous oils at the reservoir environment temperature, the main technological approach is to reduce its viscosity through the use of thermal methods $[5,6,7,8]$. Heavy oil recovery is traditionally thought of as thermal stimulation of low API gravity oil, which may range from 4 to $20^{\circ} \mathrm{API}\left(1,040\right.$ to $\left.930 \mathrm{~kg} / \mathrm{m}^{3}\right)$ [9]. The thermal methods enable production in fields considered non-commercial by conventional recovery methods. Since the heavy oils viscosity is highly temperature-dependent, the heating increases their mobility [10]. One of the most popular techniques is steam injection. Economic considerations often limit these projects since they require a big capital for their development.

The most common vehicle used to inject heat in the reservoir is saturated steam. Hot water and heated gases have been tried, but none are as effective as high-quality steam [11]. According to an "Oil \& Gas Journal" survey by Moritis (2000 apud [11]), steam enhanced oil recovery (EOR) projects accounted for 417,675 barrels of oil per day (BOPD), or $56 \%$ of the total for all enhanced recovery methods. That production rate has been essentially flat for more than 15 years. Hydrocarbon gas injection and $\mathrm{CO}_{2}$ gas injection are the only other significant contributors and amount to only 17 and 24\%, respectively.

The injected steam is generated on the surface by fixed or mobile steam generation facilities (SGF). The system is made up, besides the SGF, by distribution lines and the steam injection tubing. These tubings can be made of steel (non-insulated - conventional configuration) and insulated (for example, vacuum insulated tubing). The configuration for the continuous steam injection case is illustrated in Figure 1. Steam at high temperatures is obtained in the steam generators (1) which convert water from the liquid state to the saturated steam state, i.e., wet steam state. The generators have standard capacities of 15, 25, 50, 100 and $250 \mathrm{MMBTU} / \mathrm{h}$ and maximum operating pressures of 1,500 to 2,500 psi. The steam at the exit of the SGF has a certain quality and is transported through the distribution lines (2) to the top of injection wells. As it passes through the injection tubing (3), the steam loses thermal energy to the surrounding formation. Concepts related to the thermally insulated pipeline are presented in [12]. The heat transfer event is due to the difference between the internal well fluid and external geothermal temperatures [13]. The remnant of the heat carried by the steam that reaches the well bottom enters the oil reservoir $(4)[14,15]$. As the steam loses heat to the formation, it is condensed into hot water. The oil viscosity, diminishes and it can be produced in the production well (5) [16], arrives at the top of the well (6) and is sent to the separation facility [17]. In this work, the phenomena that occurred in stage (3) are studied.

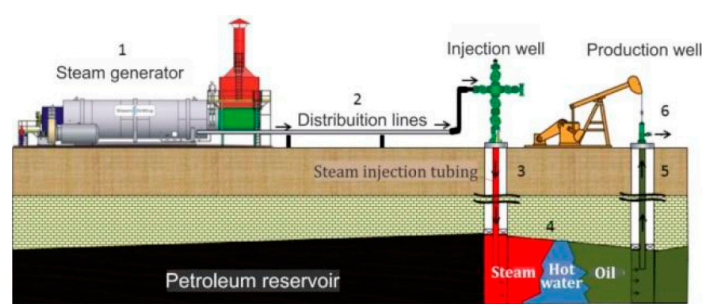

Figure 1. Continuous steam injection schematic Adapted from [17].

Although water is treated, it is not possible to completely remove the dissolved salts. Thus, in the generator, a fraction of the water is in a liquid state to maintain the salts in solution, minimizing precipitation and formation of scales on the inner walls of the SGF tubes. The scale decreases the efficiency of the facility and can come off suddenly causing clogging with disastrous consequences.

Steam injection involves heat losses to the external medium (Figure 2), and its control is a challenge. Losses at the surface and along the well can be partially controlled and minimized using, for example, mobile SGFs to be closer to the injection wellheads, and use insulation in the distribution lines and injection tubing [18]. Extensive lines cause greater losses. In the reservoir, the heat losses are not controllable. The steam heats the rock, the water, the upper and lower rock layers, and finally the oil.

Heat transfer occurs through conduction, convection, and radiation. In the well, the heat flow occurs through thermal conduction in the injection tubing, 


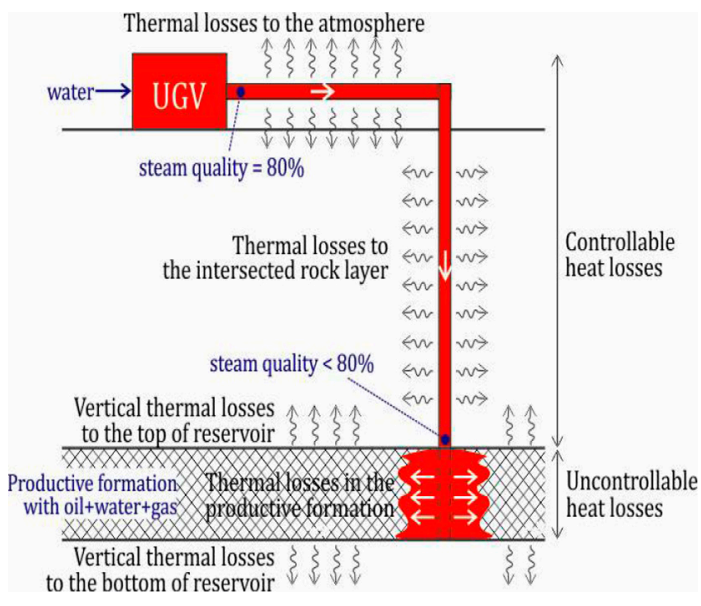

Figure 2. Surface and subsurface heat losses Adapted from [19].

in the thermal insulation, in the casing, in the cement, and the rock formation. Meanwhile, in the annular space, depending on the fluid contained in it, the heat transfer can occur by radiation, conduction, and convection [18]. A parameter that allows measuring the importance of heat transfer through convection and conduction is the Nusselt number $\mathrm{Nu}$, given by equation (1)

$$
N u=\frac{h_{c} d_{i c}}{\lambda_{m}}
$$

where $h_{c}$ is the coefficient of convective heat transfer in the wall, $d_{i c}$ a characteristic length, in the case of steam injection is the fixed inner diameter of the injection tubing and $\lambda_{m}$ the thermal conductivity of the mixture [20].

Heat losses in the flow along the injection tubing induce a progressive steam condensation, creating a liquid film on its inner surface and therefore a biphasic liquid-vapor mixture, with consequent reduction of the steam quality and enthalpy.

In order to minimize the steam heat loss along the well, the injection tubing utilized can be one made of low thermal conductivity material or thermally insulated, contributing to the maintenance of the injected steam high quality. Thus, some of the methods used for this purpose is the use of the vacuum insulated tubing (VIT), shown in Figure 3, or the use of an insulated material tubing (IMT).
The VIT technology consists in the use of two concentric tubes that are welded at their ends, creating an annular space containing a vacuum, which minimizes radial heat transfer [21, 22, 23, $24,25,26,27,28]$. However, since the junction (connector) between two tubings is not insulated, heat transfer may be significant at this location [29].

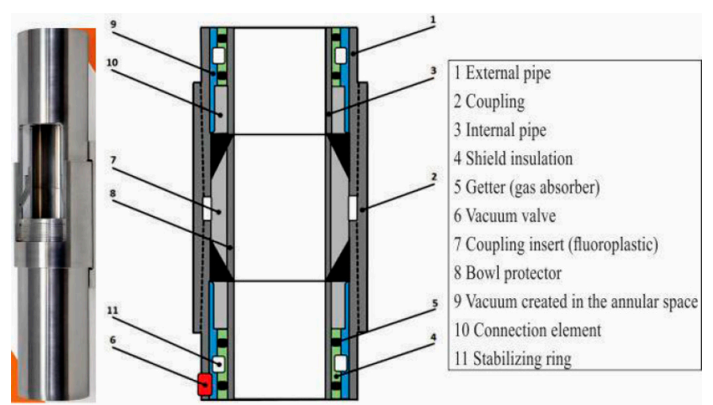

Figure 3. Vacuum insulated tubing - VIT [41].

In addition to reducing heat loss from steam to formation, VIT minimizes thermal stresses in the casing and cement and optimizes the cycles of cyclic steam stimulation to improve projects economically [24]. However, as a disadvantage, the adoption of VIT will increase costs compared to the use of conventional tubing.

In this paper, the steam injection is analyzed along with the tubing, one with conventional configuration and another with the IMT one, shown in Figure 4. The injection process was simulated in the ANSYS $\mathrm{CFX}^{\circledR} 15.0$ software [30]. Homogeneity of the mixture is assumed, implying that there are no flow regime effects and that both phases flow with the same velocity, i.e., there is no slip between them.

\section{Objective}

The objectives of these steam injection simulations are analyze the steam quality behavior, pressure and temperature profiles along the tubing for distinct flow rates and formation temperatures to maximize the outlet steam quality and consequently the thermal recovery method efficiency.

\section{MATHEMATICAL FORMULATION}

\section{Transport equations}

The mathematical behavior of the liquid-vapor mixture, subscript $m$, is described by the equations 


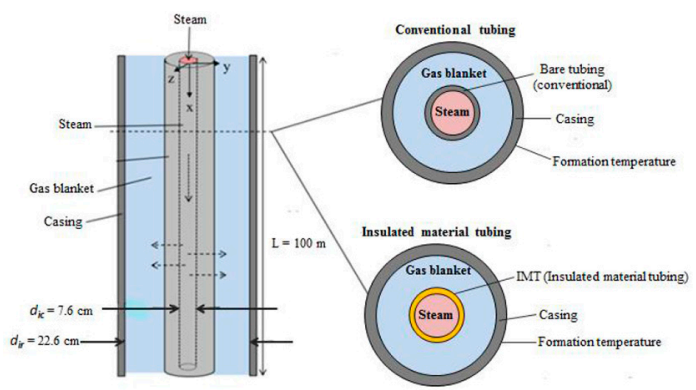

Figure 4. Problem schematic representation, which corresponds to the section 3 of Figure 1. Adapted from [38].

of continuity, equation (2), conservation of linear momentum, equation (3), and equation of energy, equation (5), detailed below

$$
\frac{\partial \rho_{m}}{\partial t}+\nabla \cdot\left(\rho_{m} \vec{u}\right)=0
$$

where $\rho_{m}$ is, the mixture density, and $\vec{u}$ is the velocity vector $[30,31]$. The first term on the left side represents the mass rate change in terms of the chosen infinitesimal element, and the second term represents the net mass flow rate out of the control surface.

Assuming the non-slip condition between the two phases, the conservation of the linear momentum equation, equation (3), can also be described in terms of a mixture, since the homogeneous multiphase model imply that the phases share the same pressure $p$ and velocity $\vec{u}$ fields [31].

$$
\frac{\partial\left(\rho_{m} \vec{u}\right)}{\partial t}+\nabla \cdot\left(\rho_{m} \vec{u} \vec{u}\right)=-\nabla p+\nabla \cdot \bar{\tau}+\rho_{m} \vec{g} .
$$

The first and second terms on the left side of the previous equation represent the local and convective acceleration, respectively, and the terms on the right side represent the pressure forces, the viscous forces and the gravitational force $\left(\vec{g}=9.8 \mathrm{~m} / \mathrm{s}^{2} \hat{i}\right)$. The stress tensor $\bar{\tau}$ is related to the velocity gradient $\nabla \vec{u}$ through

$$
\overline{\bar{\tau}}=\mu_{m e f f}\left[\nabla \vec{u}+(\nabla \vec{u})^{T}\right],
$$

$\mu_{\text {meff }}$ is the effective viscosity from the turbulence model, $\mu_{\text {meff }}=\mu_{m}+\mu_{t}$, where $\mu_{m}$ is the viscosity of the mixture, and $\mu_{t}$ is the turbulent viscosity defined by equation (10). Finally, the energy equation of the fluid, equation $(5),[30,31]$ is

$$
\frac{\partial\left(\rho_{m} h_{m}^{\text {stat }}\right)}{\partial t}+\nabla \cdot\left(\rho_{m} \vec{u} h_{m}^{\text {stat }}\right)=\nabla \cdot\left(\lambda_{m} \nabla T\right),
$$

where $\lambda_{m}$ is the mixture thermal conductivity and the term $h_{m}^{\text {stat }}$ is the mixture static enthalpy calculated by $h_{m}^{\text {stat }}-h_{m}^{r e f}=\int_{T_{r e f}}^{T} c_{\rho}(T) d T$, but since the default reference state in the ANSYS CFX-solver works with null reference enthalpy, i.e., $h_{m}^{\text {ref }}=0 j / \mathrm{kg}[30,31]$, $[30,31]$, it is rewritten as

$$
h_{m}^{\text {stat }}=\int_{T_{r e f}}^{T} C_{p}(T) d T,
$$

with $c_{p}(T)$ the specific heat at constant pressure, $T_{\text {ref }}$ is the reference temperature and $T$ the system temperature [30]. The enthalpy is the total energy stored by a pure substance from an initial state of pressure and temperature up to a certain pressure and temperature [32].

The phase equilibrium change model assumes that the mixture of the two phases is in local thermodynamic equilibrium and is especially suitable for the steam condensation flows with small fractions of the liquid mass. This means that the phases have the same temperature and that the phase change occurs very quickly. To determine the vapor mass fraction or quality $\phi$, the flow solver uses the lever rule given by equation (7) [32]

$$
\phi=\frac{h_{m}^{s t a t}-h_{s a t, l}(p)}{h_{s a t, v}(p)-h_{s a t, l}(p)}=\frac{h_{m}^{\text {stat }}-h_{\text {sat }, l}(p)}{h_{s a t, l v}(p)},
$$

where $p$ is the static pressure, $h_{s a t, 1}(p)$ and $h_{s a t, v}(p)$ are the saturation enthalpies of liquid and vapor, respectively, as a function of pressure.

With the values of $p$ and $h_{m}$, the temperature $T$ is determined by interpolation in table IAPWS-IF97. This database is obtained with a set of equations for different regions covering the following validity range: $273.15 \mathrm{~K} \leq 1,073.15 \mathrm{~K}$ for $p \leq 100 \mathrm{MPa}$ and $1073.15 \mathrm{~K}<\mathrm{T} \leq 2,272.15 \mathrm{~K}$ for $p \leq 50 \mathrm{MPa}$. In this work, the formulation extends to predict the properties of steam and water in the following temperature and pressure ranges, respectively: 450 $K \leq T \leq 900 K$ and $1 \mathrm{MPa} \leq \mathrm{p} \leq 30 \mathrm{MPa}$. Besides, 
the steam and water thermodynamic properties can also be presented in graphic form through the pressure-enthalpy diagram [32].

In the solid domains of the problem (injection tubing, annular space, and casing) as represented in Figure 4, the energy conservation equation governed by equation (8) is solved

$$
\frac{\rho_{s_{i}} c_{p i} \partial T_{s_{i}}}{\partial t}=\lambda_{s i} \nabla^{2} T_{s i}
$$

where $p_{s i}$ is the density, $C_{p i}$ is the specific heat at constant pressure, $\lambda_{s i}$ is the thermal conductivity and $T_{s i}$ is the temperature of the three solid regions involved: $i=1$ (injection tubing), $i=2$ (annular space) and $i=3$ (casing). These parameters values can be found in Table 3 .

\section{Turbulence modeling}

Flows can be classified according to the type of motion and velocity of the fluid particles, becoming unstable after a particular Reynolds number Re, equation (9).

$$
R e=\frac{\rho_{m} \bar{u}_{i n} d_{i t}}{\mu_{m}}
$$

For low Reynolds number, the flow is laminar. As for high Reynolds numbers, the flow has turbulent characteristics, a random and chaotic state of motion where velocity and pressure change continuously with time [33]. The Reynolds values at the tubing input plane with a mean velocity $\bar{u}_{\text {in }}$ and diameter $d_{i t}$ are shown in Table 2, and represents the chaotic behavior of the flow. Thus for this study is used the turbulence model $\kappa-\varepsilon$, proposed by Chou (1945 apud [33]). This model is often used with problems involving heat exchange with vapor $[34,35,36]$. It solves two different transport equations: Turbulent Kinetic Energy $\kappa$, equation (11), defined by the variation of the velocity fluctuations; and Turbulent Kinetic Energy Dissipation Rate $\varepsilon$, equation (12). The model assumes that the turbulent viscosity $\mu_{t}$ is connected to the turbulent kinetic energy $\kappa$ and dissipation $\varepsilon$ through the following ratio

$$
\mu_{t}=C_{\mu m} \rho_{m} \frac{k^{2}}{\varepsilon}
$$

where $C_{\mu m}$ is a typical model constant and equal to 0.09 [30]. The values of $\kappa$ and $\varepsilon$ are obtained from the differential transport equations for the rate of turbulent kinetic energy, equation (11), and turbulent dissipation, equation (12).

$$
\begin{gathered}
\frac{\partial\left(\rho_{m} \kappa\right)}{\partial t}+\nabla \cdot\left(\rho_{m} \bar{u} \kappa\right)=\nabla \cdot \\
{\left[\left(\mu_{m}+\frac{\mu_{t}}{\sigma_{k}}\right) \nabla \kappa\right]+P_{k}-\rho_{m} \varepsilon,} \\
\frac{\partial\left(\rho_{m} \varepsilon\right)}{\partial t}+\nabla \cdot\left(\rho_{m} \bar{u} \varepsilon\right)=\nabla \cdot \\
{\left[\left(\mu_{m}+\nabla \cdot \frac{\mu_{t}}{\sigma_{\varepsilon}}\right) \nabla \varepsilon\right]+\frac{\varepsilon}{k}\left(C_{\varepsilon 2} \rho_{m} \varepsilon\right),}
\end{gathered}
$$

$P_{K}$ is the turbulence production due to viscous forces; $\mathrm{C}_{\varepsilon 1}, \mathrm{C}_{\varepsilon 2}, \sigma_{\kappa}$, and $\sigma_{\varepsilon}$ are typical constants of the turbulence model with the respective values: $1.44 ; 1.92 ; 1.0$; and $1.3 ; \bar{u}$ is the velocity vector average in time [30].

\section{Boundary conditions}

To solve the system of equation it is necessary to delimit its solution domain, that is, to establish the boundary conditions

- Input ( $x=0$ in Figure 4): steam injection rate $q_{\text {in }}=$ $1.2 \mathrm{~kg} / \mathrm{s}$ and $3.3 \mathrm{~kg} / \mathrm{s} \mathrm{[39]}$, steam temperature $T_{\text {in }}$ $=595.59^{\circ} \mathrm{C}$ [32], steam quality $\phi_{\text {in }}=80 \%$ [8];

- Output ( $x=L$ in Figure 4): steam pressure $P_{\text {out }}$ $=11.7 \mathrm{MPa}$ [37]; and

- External border $(y=$ well radius in Figure 3): in the formation the temperature is constant and equal to two values, $T_{\text {ext }}: 283 \mathrm{~K}$ and $333 \mathrm{~K}$.

It must be remarked that we assumed the formation temperature as constant along with the well depth, since the geothermal gradient influence would not show a meaningful difference for this project, given that 400 meters is the length of our simulated tubing. A constant temperature is enough to provide us the heat exchange and its influences that we expected to see.

\section{Analyzed cases}

Four cases were considered, and their data can be observed in the following table (Table 1). 
Table 1. Main parameters of cases considered.

\begin{tabular}{|c|c|c|c|}
\hline Case & $\begin{array}{c}\text { Injection } \\
\text { rate, } \mathrm{kg} / \mathrm{s}\end{array}$ & $\begin{array}{c}\text { Inlet steam } \\
\text { quality, } \%\end{array}$ & $\begin{array}{c}\text { Formation } \\
\text { temperature, } \mathrm{K}\end{array}$ \\
\hline 1 & 1.2 & 80 & 283 \\
\hline 2 & 3.3 & 80 & 283 \\
\hline 3 & 1.2 & 80 & 333 \\
\hline 4 & 3.3 & 80 & 333 \\
\hline
\end{tabular}

The calculation of the Reynolds and Nusselt numbers of the steam-water mixture requires average values of the mixture density $\rho_{m}$, the mixture viscosity $\mu_{m}$, of the convective heat transfer coefficient $h_{c}$, and the mixture thermal conductivity $\lambda_{m}$. These data concerning the steam-water mixture at the inlet of the injection tubing are determined in the ANSYS CFD-Post and shown in Table 2.

Table 2. Properties of the steam-water mixture and additional numbers.

\begin{tabular}{|c|c|c|c|}
\hline Case & $\rho_{m}, \mathbf{k g} / \mathbf{m}^{\mathbf{3}}$ & $\mu_{m}, \mathbf{k g} /(\mathbf{m} \mathbf{~ s})$ & Re \\
\hline 1 and 3 & 186.2 & $3.2292 \times 10^{-5}$ & $1.73 \times 10^{6}$ \\
\hline 2 and 4 & 187.24 & $3.2298 \times 10^{-5}$ & $4.61 \times 10^{6}$ \\
\hline
\end{tabular}

\begin{tabular}{|c|c|c|}
\hline $\boldsymbol{h}_{c}, \mathbf{W} /\left(\mathbf{m}^{2} \mathbf{K}\right)$ & $\lambda_{\boldsymbol{m}}, \mathbf{W} /(\mathbf{m ~ K})$ & $\mathbf{N u}$ \\
\hline $1,294.12$ & 0.1688 & 582.4 \\
\hline $3,178.14$ & 0.1701 & 1,420 \\
\hline
\end{tabular}

All cases present high Nusselt values. It means that their heat transfers have a bigger influence on the convection mechanism when compared to the conduction. Since the cases 2 and 4 present bigger Nusselt values, it can be affirmed that these cases have a stronger influence of convection when compared to cases 1 and 3 .

\section{SOLUTION METHOD}

\section{Problem definition}

The system for the study of the steam heat transfer to the formation along the $100 \mathrm{~m}$ (theoretical for simulation purposes) long vertical well is formed by the steam, injection tubing, annular space containing stagnant gas at constant pressure (which will be referred to as gas blanket), steel casing column in contact with the wall of the well and the formation itself. Saturated steam is injected into the top of the injection tubing. The formation temperature is assumed constant with values equal to $283 \mathrm{~K}$ and $333 \mathrm{~K}$. The initial vapor temperature is 595.59 $\mathrm{K}$ for all situations. Since there is heat exchange between the steam and the cooler external medium, the steam quality decreases along the tubing due to the condensation process. This work is an evolution of the work developed by [38], where the tubing had only 20 meters and consequently input data also differed.

To evaluate the effect of the insulating material on the steam quality, two simplified configurations for the injection tubing are tested: conventional tubing, made of steel, and insulated material tubing (IMT) that it is made of a low conductivity material, both with an equal length of $100 \mathrm{~m}$, and equal thickness of $1.3 \mathrm{~cm}(0.51 \mathrm{in})$, Figure 4 . This study assumes that the tubings do not have threaded joints. In addition, the gas blanket is stagnant and does not present heat transfer by convection. The tubing inner diameter $d_{i c}$ is $7.6 \mathrm{~cm}$ (2.99 in); the casing inner diameter $d_{i r}$ is $22.6 \mathrm{~cm}$ ( $8.9 \mathrm{in}$ ) [39]. In this study, the cemented region between the casing outer surface and the wall of the drilled well is not included in the analysis.

The steam thermodynamic properties were obtained using the database of table IAPWS-IF97 (IAPWS International Association for the Properties of Water and Steam). When developing the IAPWS database for the ANSYS CFX ${ }^{\circledR}$ solver, the properties should be evaluated according to local pressure and temperature.

Data regarding the properties of the materials, shown in Table 3, were used.

The specific heat and density of the gas blanket were estimated from the mean temperature between the formation temperature of $283 \mathrm{~K}$ and the steam temperature $(595.59 \mathrm{~K})$. Additionally, the heat flow in the well is considered to be permanent, and the tubing concentric with the casing. For fluids characterization, the homogeneous multiphase model was used; that is, the homogeneity of the mixture was assumed along with the non-slip between phases.

This study proposes to estimate the pressure, temperature, and steam quality along the length of the injection tubing for different steam injection flow conditions and formation temperature. The condensation effects, an important phenomenon in steam injection operations, are considered. 
Table 3. Materials properties [39, 40].

\begin{tabular}{|l|c|}
\hline \multicolumn{1}{|c|}{ Material property } & Value \\
\hline Gas blanket thermal conductivity, W/(m K) & 0.05 \\
\hline Gas blanket specific heat, $\mathrm{kJ} /(\mathrm{kg} \mathrm{K})$ & 1.082 \\
\hline Gas blanket density, kg/m3 & 65.39 \\
\hline Casing thermal conductivity, W/(m K) & 44 \\
\hline $\begin{array}{l}\text { Conventional tubing thermal conductivity, } \\
\mathrm{W} /(\mathrm{m} \mathrm{K})\end{array}$ & 44 \\
\hline $\begin{array}{l}\text { Insulated material tubing (IMT) thermal } \\
\text { conductivity, W/(m K) }\end{array}$ & 0.01 \\
\hline $\begin{array}{l}\text { Injection tubing and casing specific heat, } \mathrm{kJ} / \\
\text { (kg K) }\end{array}$ & 0.434 \\
\hline Injection tubing and casing density, $\mathrm{kg} / \mathrm{m} 3$ & 7,200 \\
\hline
\end{tabular}

\section{Numerical approach}

The equations that govern the three-dimensional, turbulent, multiphase problem are solved by the finite volume technique implemented in ANSYS $\mathrm{CFX}^{\circledR} 15.0$ [30].

The flow is multiphase due to the presence of two distinct phases, steam, and condensate. However, it is considered that it is in local thermodynamic equilibrium; that is, the two phases have the same temperature and are treated as a single-phase flow. In this way, the homogeneous multiphase model is adopted, where both phases share the pressure and velocity fields, and there is no slip between them.

Although, the adopted regime is stationary, the solution is obtained through the pseudo-transient approach. ANSYS CFX ${ }^{\circledR}$ uses a solver coupled between the linear momentum and pressure equation (velocity-pressure coupling), which solves these hydrodynamic equations for $u, v, w$, and $p$ as a single system using Rhie Chow interpolation. This solution approach uses a fully implicit procedure.

The proposed approach for this work is based on three-dimensional (3D) analysis of the liquid-vapor mixture flow, assuming domain symmetry to reduce computational effort. The geometry is built with the DesignModeler software involving the domains steam, tubing (solid), annular space (solid: stagnant gas - gas blanket), casing (solid) and rock formation (Figure 5a). The spatial discretization was obtained with the Meshing software, resulting in 174,150 elements (1,350 prisms and 172,800 hexahedrons) (Figure 5b), with 30,150 elements in the steam field, 27,000 elements in each field of tubing and casing, and 90,000 elements in the gas blanket domain. This level of refinement is selected after the mesh test described in the next section.

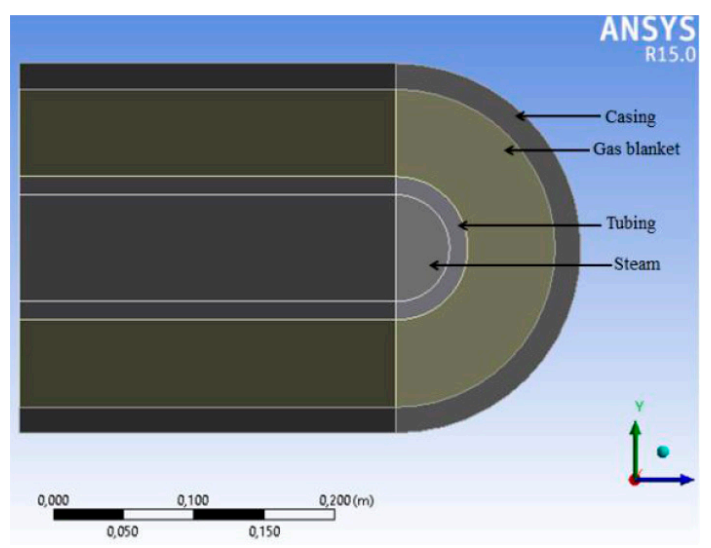

Figure 5a. Part of domain.

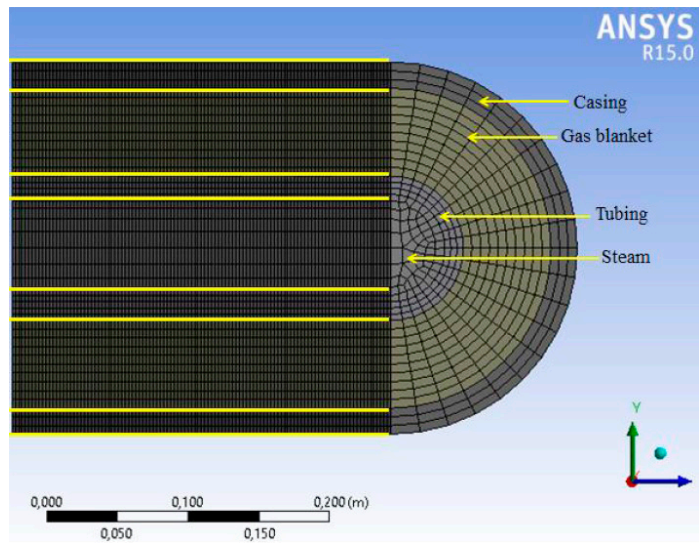

Figure 5b. Part of discretized domain.

After incorporating the boundary conditions, steam and involved solids properties, as well as operational parameters of the injection, the problem is solved with the CFX-Solver manager, and then the results are post-processed in ANSYS CFD-Post. With an average of 635 iterations and a maximum residual level of $5.0 \times 10^{-4}$, the simulations were completed. The average simulation time was 21 minutes and 29 seconds on a computer with the following configurations: Intel (R) Core i5-2350M, CPU @ 3.60GHz, 8.0GB of RAM, and 64-bit operating system.

\section{Mesh test}

It can be observed from Figure 6 that the most refined meshes did not show sufficient discrepancy with the 
results of the simplest mesh, the 174,150 elements one. The simulation time for meshes with the total of $174,150,387,000$, and 774,000 elements were respectively $21.5,49.2$, and 106.6 minutes. Based on these facts, it is concluded that the mesh with 174,150 elements is the most adequate for this work.

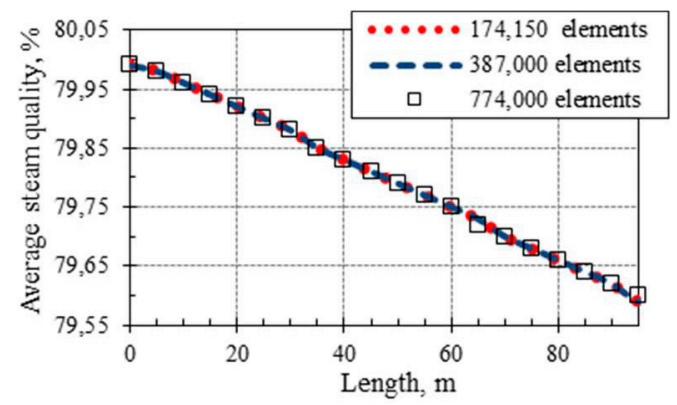

Figure 6. Steam quality behavior with the mesh refinement.

\section{RESULTS}

The presented results are average values calculated in the $y-z$ contour by equation (13)

$$
\theta_{\text {ave }}=\frac{\sum_{i=1}^{n} \theta_{i} A_{i}}{\sum_{i=1}^{n} A_{i}},
$$

where $=\theta_{\text {ave }}$ is the average value of the variable of interest in the $\mathrm{y}-\mathrm{z}$ contour, $i$ is the element index, $A_{i}$ the element area, $\theta_{i}$ the variable of interest value in the element $i$ and $n$ is the number of elements in the domain of interest. The results presented in the following are in the steam domain where $n$ $=48$, and the variables of interest are pressure $p$, temperature $T$ and steam quality $\phi$.

\section{Pressure and temperature behaviors along the tubing}

Initially the behaviors of the pressure and temperature are verified in Figures 7 and 8, respectively, both regarding the well depth $x$, i.e., along with the tubing. Since it is a steady system, as it was previously assumed, the velocity and the pressure at a certain point do not vary with time. The temperature also does not change even with the formation of temperature changes. These external changes only affect the steam quality because there is loss of latent heat and the lower the formation temperature, the lower the mixture enthalpy and thus the quality along the tubing will also be lower [38].

Because of the vertical configuration, the hydrostatic column weight (caused by the steam condensation) increases with the depth, i.e., along with the tubing, and there is also a pressure drop due to friction it increases with a lower one (case 1), Figure 7.

By ignoring the acceleration effects, the overall pressure gradient $\left.\frac{\partial p}{\partial x}\right|_{T}$ is $\left.\frac{\partial p}{\partial x}\right|_{h}$ equal to the sum of the hydrostatic component with the friction component, $\frac{\partial p}{\partial x_{f}}$, i.e. $\left.\frac{\partial p}{\partial x}\right|_{T}=\left.\frac{\partial p}{\partial x}\right|_{h}+\left.\frac{\partial p}{\partial x}\right|_{f}$ [38]. Under the analyzed conditions, case 2 shows a pressure drop because of its bigger friction, since its flow rate is higher, that decreases its overall pressure more than the condensation increases (Figure 7), and consequently this decreases also its temperature (Figure 8). The friction losses dominate case 2, decreasing the total pressure. The hydrostatic column weight contribution dominates case 1 where the flow rate is lower, thus; as a result, the total pressure increases.

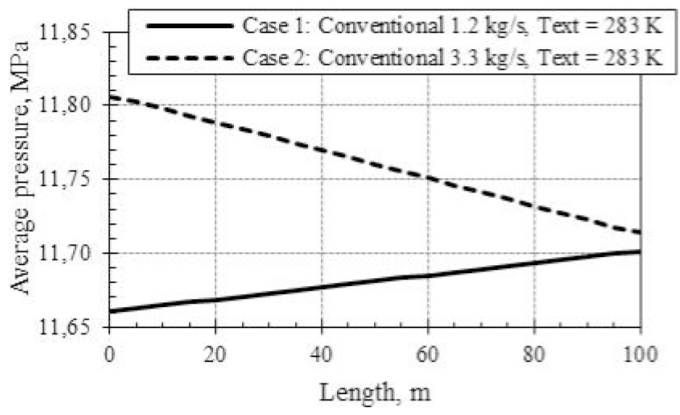

Figure 7. Steam injection flow rate influence on the average pressure along with the tubing.

While in case 1 the mixture temperature increases with the well depth, i.e., along with the tubing and the temperature gradient $\left.\frac{\partial T}{\partial x}\right|_{\text {Case } 1}=0.004 \mathrm{~K} / \mathrm{m}$, in case 2 it decreases $\left.\frac{\partial T}{\partial x}\right|_{\text {Case } 2}=-0.005 \mathrm{~K} / \mathrm{m}$, and since this one has a higher flow rate the saturation temperature is bigger along with the saturation pressure required to maintain this process. This behavior observed in Figures 7 and 8. 


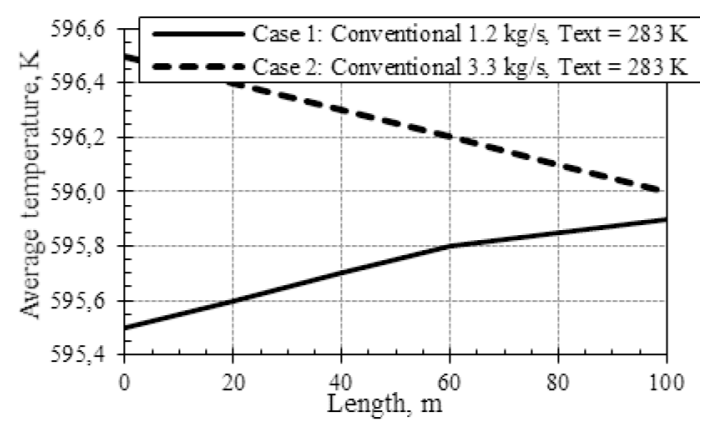

Figure 8. Steam injection flow rate influence on the average temperature along tubing.

As the pressure imposed in all cases studied in the well output is $11.7 \mathrm{MPa}$, the temperature in this boundary will be equal to $595.9 \mathrm{~K}$ for case 1 and 596 $\mathrm{K}$ for case 2. Although the stipulation of the steam initial temperature is $595.59 \mathrm{~K}$ at the tubing inlet is perceived a slight decrease of the same in case 1 and an increase in case 2 . For each value of absolute steam pressure calculated in the output, there is a saturation temperature value corresponding. Thus, for case 1 there is an initial pressure equal to 11.66 $\mathrm{MPa}$ and $595.5 \mathrm{~K}$ saturation temperature. For case 2 , the pressure at the beginning was calculated to be $11.80 \mathrm{MPa}$ and temperature of $596.5 \mathrm{~K}$.

When compared to Pereira's work [38] it must be highlighted that now with a 400 meter tubing a different pressure and temperature behavior can be seen: the decreasing pressure/temperature for higher flow rates (case 2 in Figures 7 and 8). In the previous works, with a 20 -meter tubing, such profile could not be reached.

\section{Steam quality behavior along the tubing}

Figures 9 and 10 show the variation of steam quality in the two tubing configurations (conventional and IMT -insulated material tubing), for two steam injection flow rates and two formation temperatures $(283 \mathrm{~K}$ and $333 \mathrm{~K})$. The quality variation is bigger to the $1.2 \mathrm{~kg} / \mathrm{s}$ flow rate, Figures 9 and 10 . In the conventional tubing, the quality has a larger drop in comparison to the IMT, or a lower steam fraction will reach the end of the route. The steam quality decrease along the IMT setting is lower because of its low thermal conductivity. Regarding the influence of the outside temperature, we can see a more pronounced decline in the steam quality with the lower external temperature, Text $=283 \mathrm{~K}$, for both tubing settings.

In conventional tubing, the influence of the injection flow rate is notorious. Higher flow rates favor the steam quality maintenance, which is desired in thermal methods, once the fluid has less time to exchange heat with the surrounds.

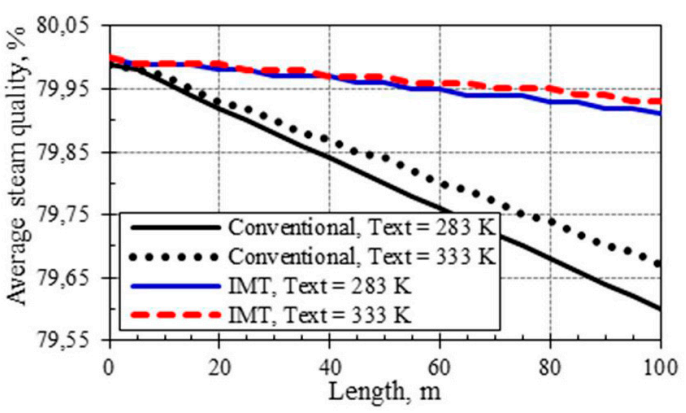

Figure 9. Steam quality behavior along the tubing with $1.2 \mathrm{~kg} / \mathrm{s}$ flow rate.

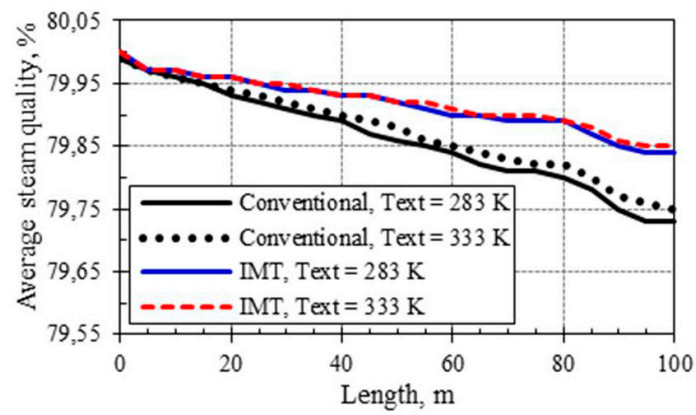

Figure 10. Steam quality behavior along the tubing with $3.3 \mathrm{~kg} / \mathrm{s}$ flow rate.

Working with a twenty times greater depth, when compared to [38], it is possible to see (Figure 9) a higher quality drop.

\section{Steam quality at the tubing outlet}

The vapor mass fraction field, or steam quality, at the outlet of the two tubing configurations, conventional and IMT, are shown in Figure 11, both with a formation temperature of $283 \mathrm{~K}$. Although the variations are small, the steam quality is higher in the center of the column (represented by the white color), decreasing radially towards the wall (black color) representing the liquid 
that results from the vapor condensation. In the IMT, Figure 11b, that the plot scale shows higher qualities than the ones from Figure 11a can be seen. The conventional tubing contour plot, which is expected since the IMT has a lower thermal conductivity, so the average quality value is lower in the conventional configuration $(79.60 \%)$ versus $79.91 \%$ of the IMT one.

The difference between maximal and minimal steam quality values are $27 \times 10^{-5}$ (or $0.034 \%$ related to the maximal value) and $26 \times 10^{-5}$ (or $0.032 \%$ related to the maximal value) for the conventional and IMT configurations, respectively. It means that the steam quality distribution in the section, at least at the outlet boundary, is almost not affected by the low thermal conductivity of the IMT.

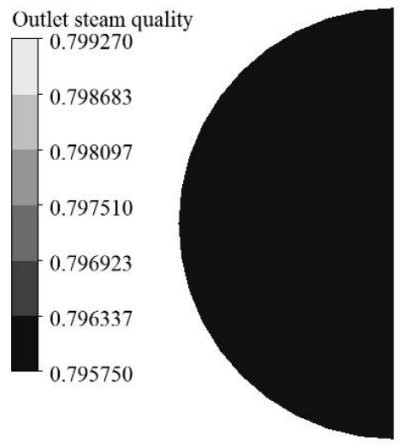

(a) Conventional tubing

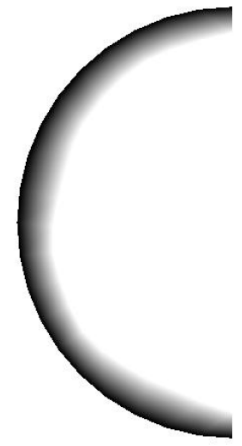

(b) IMT
Figure 11. Vapor mass fraction (quality) contour plots at the outlet boundary of the injector well, for case 1 , with formation temperature equal to $283 \mathrm{~K}$.

The thermal conductivity effect of the column on the steam fraction reaching the tubing outlet is highlighted in Figure 12. In general, the increase in conductivity is detrimental to the injection process. However, this behavior can be controlled by increasing the steam injection flow rate, which requires more robust systems on the surface. It is interesting to note in this figure that the thermal conductivity $\lambda$ improves the performance of the system for values below the critical one $\lambda_{\text {crit }}$, that is $\lambda \leq \lambda_{\text {crit }}$. Above the thermal conductivity critical value $\left(\lambda>\lambda_{\text {crit }}\right)$ steam quality is not more influenced by the type of insulating material used.

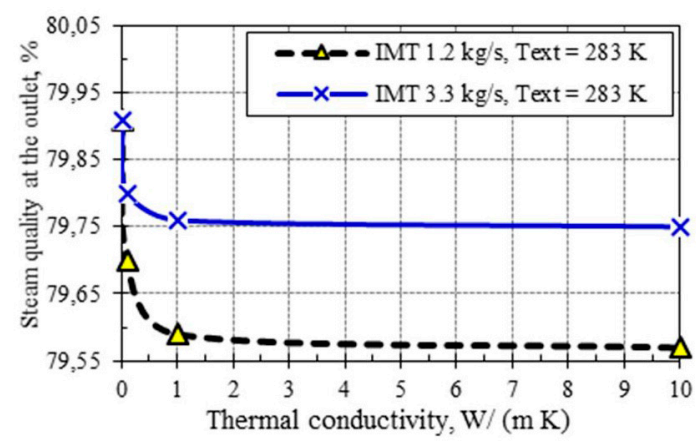

Figure 12. Steam quality at the outlet plane of the injector well versus thermal conductivity of the IMT.

It was not possible to compare the results of this work with other works since none similar was found. The ones involving steam quality drop along the tubes usually are found in different circumstances of pressure, temperature, and initial steam quality $[22,29,39]$. Others evaluate different characteristics such as the waves behavior of the liquid film along the tube, which diverge, from our objective here [34].

It must be highlighted that our 400-meter length domain, was only possible due to extensive research for bottom hole data. Moreover, for it to be run in the tool ANSYS CFX the maximum residual level when compared to Pereira's [38] had to be restricted.

\section{CONCLUSIONS}

The multiphase, turbulent, non-isothermal, threedimensional problem was solved numerically with the ANSYS CFX software.

The comparison between the results obtained for a conventional tubing and an insulating material one assured that the IMT (insulated material tubing) has the best efficiency when it comes to maintaining the steam quality.

Using a bigger length tubing, in comparison to previous works [38] proved that: the friction losses could dominate the process, but in this work, this only happened with the higher flow rate. The rate also shows stronger influence in the steam quality when the conventional tubing is utilized: lower flow rate in a conventional setting means higher quality loss. 
It could also be observed that the lower rock formation temperature caused bigger quality drops as expected since de temperature variation is also higher.

In the future, the same process will be addressed in with even larger tubing where it is expected to observe the total pressure drop for both flow rates and an even bigger quality drop since there will be more time for the steam to exchange heat.

\section{ACKNOWLEDGEMENTS}

The authors are grateful to the scholarship program PIBIC Ufes for their financial support. We also would like to thank Edson de Jesus Segantine, Suellen Freire Rigatto, Isabella Braga Pereira and Professor Daniel da Cunha Ribeiro for their support that was indispensable since the very beginning. We also thank the SPE Ufes student chapter <spe. ufes.br $>$ for enabling the free use of the OnePetro platform <onepetro.org > of Society of Petroleum Engineers (SPE) at the UFES campus in São Mateus, ES, Brazil.

\section{REFERENCES}

[1] R.G. Miller and S. R. Sorrell. "The future of oil supply”. Phil. Trans. R. Soc. A. Vol. 372 No 2006, pp. 20130179. 2014. DOI: 10.1098/ rsta.2013.0179.

[2] A. Muggeridge, A. Cockin, K. Webb, H. Frampton, I. Collins, T. Moulds and P. Salino. "Recovery rates, enhanced oil recovery and technological limits". Phil. Trans. R. Soc. A. Vol. $372 \mathrm{~N}^{\circ}$ 2006, pp. 20120320. 2014. DOI: 10.1098/rsta.2012.0320.

[3] J.K. Coelho, M.D. Pena and O.J. Romero. "Pore-scale modeling of oil mobilization trapped in a square cavity (in Portuguese)". Revista IEEE América Latina. Vol. 14 $\mathrm{N}^{\circ}$ 4, pp. 1800-1807. 2016. DOI: 10.1109/ TLA.2016.7483518.

[4] K.B. Santos, O.J. Romero, A.P. Meneguelo and D.C. Ribeiro. "A numerical investigation of immiscible water-oil displacement in simplified porous media (in Portuguese)". Revista IEEE América Latina. Vol. 14 $\mathrm{N}^{\circ}$ 5, pp. 2175-2183. 2016. DOI: $10.1109 /$ TLA.2016.7530411.

[5] S. Thomas. "Enhanced Oil Recovery An Overview". Oil \& Gas Science and
Technology - Rev. IFP. Vol. $63 \mathrm{~N}^{\mathrm{o}} 1$, pp. 9-19. 2008. DOI: https://doi.org/10.2516/ ogst:2007060.

[6] R.M. Butler. "Thermal recovery of oil and bitumen". Prentice Hall. 496 p. New Jersey. 1991.

[7] V. Alvarado and E. Manrique. "Enhanced Oil Recovery: An Update Review". Energies. Vol. 3, pp. 1529-1575. 2010. DOI: 10.3390/ en3091529.

[8] D.W. Green and G.P. Willhite. "Enhanced oil recovery". Richardson. TX, Henry L. Doherty Memorial Found for AIME Society of Petroleum Engineers. 1998.

[9] P.J. Briggs, R.P. Baron, R.J. Fulleylove and M.S. Wright. "Development of heavy-oil resources". J. of Pet. Technol. Vol. $40 \mathrm{~N}^{\circ} 2$, pp. 206-214. 1988. DOI: 10.2118/15748-PA.

[10] M. Latil. "Enhanced Oil Recovery". Editions Technip. 1980.

[11] Petrowiki. "Thermal recovery by steam injection". Available at: http://petrowiki. org/Thermal_recovery_by_steam_injection. Access in: November 27 2016.

[12] R. Bruschi, L. Gambelli, P. Pierangeli and E. Raffaeli. "Double Pipe Ensures Reliable Insulation of Offshore Pipelines". ASME J. Energy Resour. Technol. Vol. $110 \mathrm{~N}^{\circ} 2$, pp. 59-67. 1988. DOI: 10.1115/1.3231367.

[13] T. W. Stones, G. Li and I. Pallister. "A comparison of analytic and segmented heat and quality loss in thermal steam injection wells". SPE Reservoir Simulation Symposium. Woodlands, TX, USA. Feb. 18-20, 2013. DOI: 10.2118/163639-MS.

[14] H. Wu, Q. Du, J. Hou, J. Li, R. Gong, Y. Liu and Z. Li. "Characterization and Prediction of Gas Breakthrough With Cyclic Steam and Gas Stimulation Technique in an Offshore Heavy Oil Reservoir". ASME J. Energy Resour. Technol. Vol. 139 No 3, pp. 0328011 - 032801-9. 2016. DOI: 10.1115/1.403485.

[15] P. Liu, H. Zheng and G. Wu. "Experimental Study and Application of Steam Flooding for Horizontal Well in Ultraheavy Oil Reservoirs". ASME J. Energy Resour. Technol. Vol. $139 \mathrm{~N}^{\mathrm{o}}$ 1, pp. 012908-1 012908-9. 2016. DOI: 10.1115/1.4035254.

[16] O.J. Romero and A. Hupp. "Subsea Electrical Submersible Pump Significance in Petroleum Offshore Production”. ASME J. Energy 
Resour. Technol. Vol. 136 NNo $^{\circ}$, pp. 012902-1 - 012902-8. 2013. DOI: 10.1115/1.4025258.

[17] E. Dias Jr and O. J. Romero. "Estudo da transferência de calor durante a injeção de vapor em poços de petróleo". Latin American Journal of Energy Research. Vol. $1 \mathrm{~N}^{\mathrm{o}} 1$, pp. 46-53. 2014. DOI: 10.21712/lajer.2014. v1.n1.p.46-53.

[18] M.A.F. Rodrigues. "Estudo paramétrico da segregação gravitacional na injeção contínua de vapor (in Portuguese)". Dissertação de Mestrado. Universidade Federal do Rio Grande do Norte. Natal, RN. 2008.

[19] O.J. Romero. "Enhanced oil recovery (in Portuguese)". Class notes, Petroleum Engineer undergraduate course in the Federal University of Espírito Santo (UFES), Brazil. 2017.

[20] F.P. Incropera, D.P. Dewitt, T.L. Bergman and A. S. Lavine. "Fundamentals of Heat and Mass Transfer". Ed. LTC. Rio de Janeiro, RJ. 2008.

[21] P.D. Pattillo, J.E. Bellarby, G.R. Ross, S.W. Gosch and G.D. Mclaren. "Thermal and Mechanical Considerations for Design of Insulated Tubing". SPE/IADC Drilling Conference. SPE Paper No 79870-PA. Amsterdam, The Netherlands. Feb, 19-21, 2003. DOI: $10.2118 / 79870-P A$.

[22] Y. Kang, R. Samuel, A. Gonzales and Z. Liu. "Heat Transfer Modeling of Wellbore with Vacuum-Insulated-Tubing (VIT)". SPE Thermal Well Integrity and Design Symposium. SPE Paper No 178449-MS. Banff, Alberta, Canada, Nov. 23-25, 2015. DOI: $10.2118 / 178449-M S$.

[23] J.H. Azzola, P.D. Pattilo, J.F. Richey and S.J. Segreto. "The heat transfer characteristics of vacuum insulated tubing". SPE Annual Technical Conference and Exhibition. SPE Paper No 90151-MS. Houston, Texas, USA. Sep. 26-29, 2004. DOI: 10.2118/90151-MS.

[24] Y. Zhang, Y. Lei, J.H. Xiao, E. Klotz and J. Shen. "Vacuum Insulated Tubing in Thermally Assisted Heavy Oil Production". SPE Thermal Well Integrity and Design Symposium. SPE Paper No $178483-\mathrm{MS}$. Banff, Alberta, Canada, Nov. 23-25, 2015. DOI: 10.2118/178483-MS.

[25] K. Falk, B. Karpuk and P. Pelensky. "A review of insulated concentric coiled tubing installations for single well, steam assisted gravity drainage". SPE/ICoTA North American Coiled Tubing Roundtable. SPE Paper N ${ }^{\circ}$ 36333-MS. Montgomery, TX. Feb. 26-28, 1996. DOI: 10.2118/36333-MS.

[26] H. Gu, L. Cheng, S. Huang, B. Li, F. Shen, W. Fang and C. Hu. "Steam injection for heavy oil recovery: Modelling of wellbore heat efficiency and analysis of steam injection performance, Energy Conversion and Management". Elsevier. pp. 167-177. 2015. DOI: 10.1016/j.enconman.20NAYS3.057.

[27] M.S. Lombard. "What every engineer should know about vacuum insulated tubing”. SPE Western Regional Meeting. SPE Paper $N^{\circ}$ 153837-MS. Bakersfield, California, USA. March 19-23, 2012. DOI: 10.2118/153837-MS.

[28] Y. Nian, W. Cheng, T. Li and C. Wang. "Study on the effect of wellbore heat capacity on steam injection well heat loss". Elsevier. Applied Thermal Engineering, pp. 763-769. 2014. DOI: 10.1016/j.applthermaleng.2014.05.056.

[29] M.V.D. Ferreira, J. Barcelos, C.A.S. Costa, J.R. Barbosa Jr. and A.K. Silva. "Thermal analysis of vacuum insulated tubing (VIT) for offshore oil wells". 15 $5^{\text {th }}$ Brazilian Congress of Thermal Sciences and Engineering. Belém, PA, Brazil. Nov. 10-13, 2014.

[30] Ansys CFX. "Solver Theory Guide". Ansys CFX Release 15.0. Ansys, Inc., 372 f. USA. 2013.

[31] E.S. Rosa. "Escoamento Multifásico Isotérmico (in Portuguese)". Bookman. Porto Alegre, RS. 2012.

[32] R.E. Sonntag, C. Borgnakke and G.J.V. Wylen. "Fundamentos da Termodinâmica (in Portuguese)". Ed. Edgard Blücher. São Paulo, SP. 2003.

[33] D.C. Wilcox. "Turbulence modeling for CFD”. DCW Industries Inc. La Cañada, CA. 1993.

[34] S.K. Dahikar, A.A. Ganguli, M.S. Gandhi, J.B. Joshi and P.K. Vijayan. "Heat Transfer and Flow Pattern in Co-current Downward Steam Condensation in Vertical Pipes-I: CFD Simulation and Experimental Measurements". The Canadian Journal of Chemical Engineering, pp. 959-973. Ottawa/ Ontario, Canada. May, 2013. DOI: 10.1002/ cjce. 2172 . 
[35] Z. F. Fayal, B. Lakhdar and N. Zoubir. "Horizontal Well Performance Flow Simulation CFD-Application". SPE Production and Operations Conference and Exhibition. SPE Paper $N^{\circ} 133269$ MS. Tunis, Tunisia. Jun. 8-10, 2010. DOI: 10.2118/133269-MS.

[36] Y. Zhou and S.N. Shah. "Fluid Flow in Coiled Tubing: CFD Simulation". Canadian International Petroleum Conference. SPE Paper No 2003-212. Calgary, Alberta, Canada. Jun. 10-12, 2003. DOI: 10.2118/2003-212.

[37] L.D. Wheaton. "Measurement of Steam Injection Tubing Heat Losses Using Pressure/Temperature Survey Data”. SPE International Thermal Operations Symposium. Bakersfield, California. Feb. 7-8, 1991. DOI: 10.2118/21524-MS.
[38] I.B. Pereira, D.C. Ribeiro and O.J. Romero. "Three-Dimensional Modelling of Heat Transfer in Wellbore During Steam Injection Process (in Portuguese)". Revista IEEE América Latina. Vol. 15 No 4, pp. 690-697. 2017. DOI: 10.1109/TLA.2017.7896396.

[39] S. Karra, N. Chudiak, A. Sinha and E.G. Boser. "SAGD Vacuum Insulated Tubing vs. Bare Tubing - Concentric and Eccentric Configurations: A Comparative Thermal Computational Fluid Dynamics Study". SPE Heavy Oil Conference. SPE Paper $N^{\circ}$ 170177-MS. Calgary, Alberta, Canada. Jun. 10-12, 2014. DOI: 10.2118/170177-MS.

[40] B. Wischnewski. "Peace software". Available at: http://www.peacesoftware.de/einigewerte/ luft_e.html. Access in: November 20, 2016.

[41] TMK. Available at: https://www.tmk-group. com/VIT Access in: July 25, 2018. 